\title{
Residual velocity of the non-deformable projectile after perforating the ultra-high performance fibre reinforced concrete
}

\author{
R. Sovják ${ }^{1}$, T. Vavřiník ${ }^{1}$, M. Frydrýn ${ }^{2}$, T. Mičunek $^{2}$, \\ J. Zatloukal ${ }^{1}$ \& P. Máca ${ }^{1}$ \\ ${ }^{I}$ Experimental Centre, Faculty of Civil Engineering, \\ Czech Technical University in Prague, Czech Republic \\ ${ }^{2}$ Department of Forensic Experts in Transportation, \\ Faculty of Transportation Sciences, \\ Czech Technical University in Prague, Czech Republic
}

\begin{abstract}
This contribution is focused on the optimal fibre content in the ultra-high performance fibre reinforced concrete (UHPFRC) mixture with respect to the residual velocity of the non-deformable projectile after perforating the UHPFRC slabs. Impact velocity of the non-deformable projectile was in the range of $700 \mathrm{~m} / \mathrm{s}$. The UHPFRC used in this study exceeded $150 \mathrm{MPa}$ in uniaxial compression and tensile strength was around $10 \mathrm{MPa}$. In total 24 UHPFRC slabs with different fibre content were tested for impact loading. In addition, 8 slabs were tested for comparison including high strength concrete (HSC) and conventional fibre reinforced concrete (FRC). It was verified experimentally that UHPFRC had an excellent impact resistance compared to conventional materials such as FRC or HSC. Further it was found that optimal fibre content in UHPFRC for impact resistant structures is $2 \%$ by volume. Usage of less than $2 \%$ of fibre concrete by volume led to higher residual velocity of the projectile after perforating the slab and also to higher debris fragment mass.

Keywords: UHPFRC, fibre content, semiautomatic rifle, projectile impact, perforation, residual velocity, debris fragment mass.
\end{abstract}




\section{Introduction}

This study focuses on the evaluation of the residual velocity of the nondeformable projectile after perforating Ultra High Performance Fibre Reinforced Concrete (UHPFRC). UHPFRC can be characterized as a composite material with a high cement and silica fume content, a low water-binder ratio and absence of coarse aggregate, i.e. aggregate larger than $1 \mathrm{~mm}$. Straight steel micro fibres were used in the UHPFRC mixture in order to improve ductility of the material. In addition, utilization of steel micro fibres in the mixture brought the tensile hardening behaviour. UHPFRC used in this study was subjected to a series of tests that simulated the impact of fast-flying projectile with impact velocity in the range of $700 \mathrm{~m} / \mathrm{s}$. The striking kinetic energy was approximately $2000 \mathrm{~J}$. Projectile used in this study was chosen in order to simulate high-speed lowweight explosions generated projectile or direct armed attack caused by the small arms.

\subsection{Research significance}

Impact resistance of concrete structures can be increased by several ways such as implementation of steel lining, making the slab a double-layered composite slab with an elastic absorber and employing fibre reinforced concrete (FRC) or high strength concrete (HSC) as the slab material [1]. It is well-known that FRC has good capacity to absorb impact energy [2]. However, several authors suggested that UHPFRC has much greater capacity to withstand impact loading [3, 4].

Resistance of targets made of high performance concrete subjected to projectile impact was studied by several researches. Influence of matrix composition [5, 6], compressive strength and curing temperature [7], panel thickness [8] or impact velocity [9, 10] were studied extensively. Very little studies have been focused on the estimation of the optimal fibre content in the UHPFRC mixture. In this research only fibre content varied from $0.0 \%$ to $2.5 \%$ by volume where other input parameters remained unchanged during entire experimental program.

Previous studies showed that the optimal fibre content with respect to the inservice deformable projectile impact lies around $2.0 \%$ by volume $[11,12]$. Purpose of this contribution was to extend a previous case study and find the optimal fibre content with respect to the residual velocity of the non-deformable in-service projectile after perforating UHPFRC slab. Proper dosage of the fibres is, above the price, a crucial factor in terms of workability, mechanical properties and also dynamic response.

\section{Materials}

UHPFRC used in this study was developed with respect to the components available commonly in the Czech Republic. Material design process was fully described elsewhere [13, 14]. Briefly, the UHPFRC was mixed in the conventional mixers and the slabs were cured in the water tanks. In this study 
fibre content was selected as the main test variable. Fibres used in this study were $13 \mathrm{~mm}$ long with diameter equal to $0.15 \mathrm{~mm}$. Fibres were straight with tensile capacity of $2800 \mathrm{MPa}$. Straight fibres provided good trade-off between workability and mechanical properties of the resulting mixture. The compressive strength of the resulting mixture exceeded $150 \mathrm{MPa}$. Compressive strength did not exhibit any variation within different fibre content. On the other hand, uniaxial tensile strength exhibited strong dependence on the actual fibre content. Maximal tensile strength was in the range of $10 \mathrm{MPa}$ when fibre content was $3 \%$ by volume [15].

HSC was made from standard $60 \mathrm{MPa}$ mix. FRC slabs were constructed using maximal aggregate size of $8 \mathrm{~mm}$ and high tensile $(2000 \mathrm{MPa})$ steel fibres that were $30 \mathrm{~mm}$ long with aspect ratio equal to 80 . Fibres used for FRC mixture had hooked ends that are generally considered as the best form of anchorage. The fibre content in FRC was designed to be $0.63 \%$ as the best range of steel fibres with hooked ends for impact resistance concrete lies between $0.5 \%$ and $0.75 \%$ by volume [9].

\section{Experimental program}

Previous study confirmed that $50 \mathrm{~mm}$ thick UHPFRC slab is able to stop the non-deformable projectile [16]. On the basis of this finding a thickness of the slabs was reduced to $45 \mathrm{~mm}$. This thickness provided adequate assurance for perforation of the slab and ensured a sufficient depth for a uniform dispersion of fibres. In total 24 UHPFRC slabs with different fibre content (i.e. $0.0 \%, 0.5 \%$, $1.0 \%, 1.5 \%, 2.0 \%$ and $2.5 \%$ ) were tested for impact loading. Projectile hit the centre of the slab under the right angle. In this configuration the projectile had the biggest damage potential. The shooting distance was 20 meters and the shooting chronograph was located approximately 1 metre from the gun muzzle. The impact velocity was determined from the muzzle velocity so that the muzzle velocity was reduced by the value given by Kneubuehl [17]. The difference between the muzzle velocity and the impact velocity of the projectile was approximately $20 \mathrm{~m} / \mathrm{s}$. High speed camera was implemented to measure the residual velocity of the projectile. The high speed camera captured 0.6 meters between the back side of the specimen and the set of steel plates (Figure 1). High speed camera was set to sampling frequency of 4000 frames/s. Sampling frequency was based on the assumptions of the residual velocity. Set of $1 \mathrm{~mm}$ thick steel plates was adopted from tests performed by Bludau et al. [18]. It was assumed that a perforation o 1.5 plates is equal to serious injury on the human body. Debris fragment mass was calculated by weighing the slab before and after each test.

Impact was simulated as a hit of full metal jacket ammunition with mild-steel core, noted as non-deformable projectile. Yield strength of the mild-steel core was $550 \mathrm{MPa}$. The weight of the ogive-nose shaped steel jacketed projectile was 8.04 grams. The length of the non-deformable projectile was $26.7 \mathrm{~mm}$ and the diameter of the projectiles was $7.92 \mathrm{~mm}$ (Figure 2). The projectile was fired from semiautomatic rifle $\mathrm{CZ} 858$, calibre $7.62 \times 39$, which is a civilian version of 
former Czechoslovak military assault rifle SA-58. The ammunition used is approved for civilian use.

Each slab was placed in a special mount developed for the purpose of this study in order to prevent movement of the specimen during projectile impact. The mount was provided with four screws located in the corners of the slabs from both sides in order to simulate point supports.
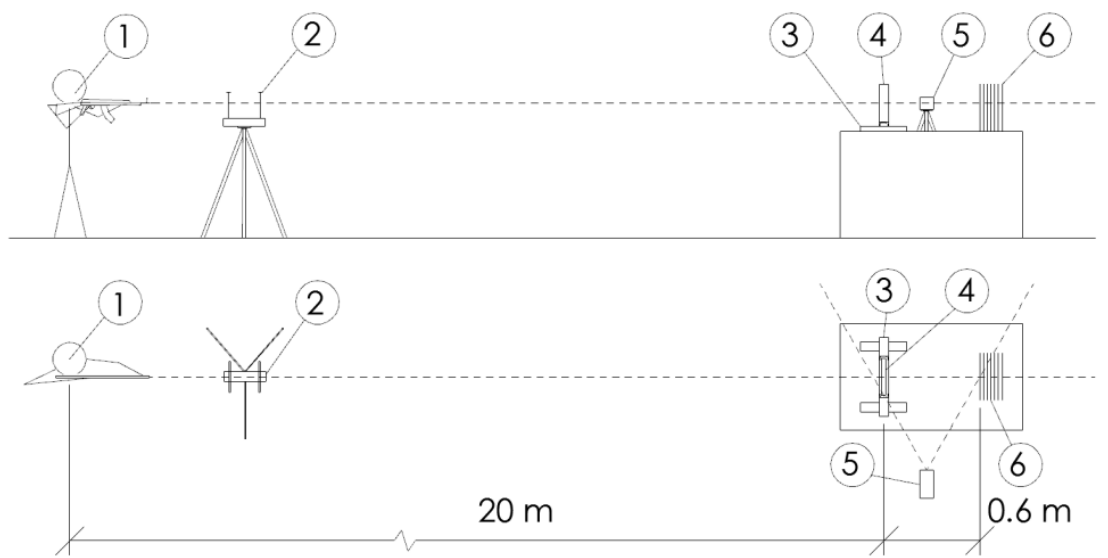

Figure 1: Experimental setup: 1) shooter, 2) shooting chronograph, 3) mount for the slab, 4) slab, 5) high-speed camera, 6) set of $1 \mathrm{~mm}$ thick steel plates.

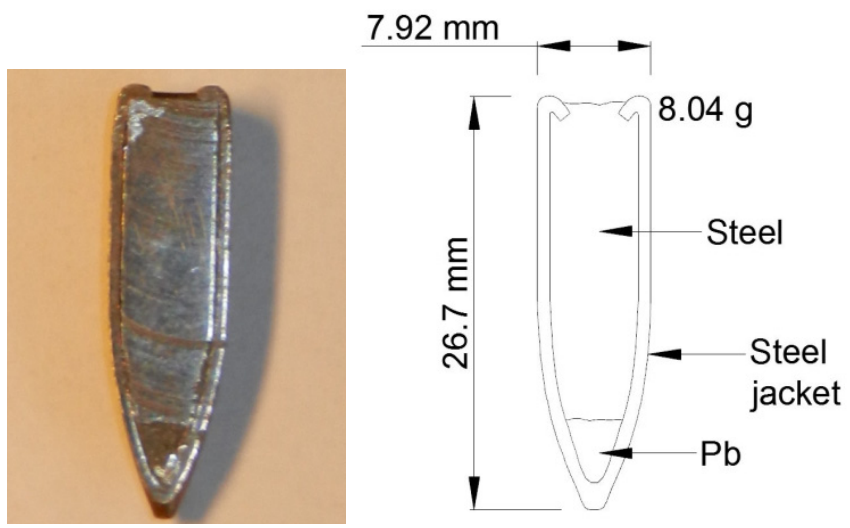

Figure 2: Cross-section of the ogive-nose shaped projectile.

\section{Results and discussion}

Records from the high speed camera and imprints in the steel plates revealed that the projectile trajectory did not follow initial course after perforating the slab. 
This happened due to the anisotropic fracture process in concrete structure [19]. The residual velocity was determined using solid angle, which was specified from camera records and imprints in steel plates. The impact velocity was calculated from the muzzle velocity using the shooting chronograph and reduction defined by Kneubuehl [17]. Steel jacket was separated from the steel core during the penetration process. In some cases the steel jacket was retained in the slab but in some cases continued its path up to the first plate. Steel core with measured yield strength of $550 \mathrm{MPa}$ perforated UHPFRC slab entirely and subsequently was retained by the set of the steel plates. Residual velocity of the projectile was taken as a residual velocity of the steel core derived from the solid angle. Residual velocity was related to the impact velocity due to unstudied scatter in the impact velocities. The scatter in impact velocities was circa $15 \mathrm{~m} / \mathrm{s}$.

Experimental results showed that implementation of small fibre content to the UHPFRC mixture (i.e. $0.5 \%$ and $1.0 \%$ ) does not significantly improve the resistance to projectile impact in terms of the residual velocity compared to the plain UHPC mixture (i.e. UHPFRC with $0 \%$ of fibre content). However, significant improvement is evident between $1.0 \%$ and $2.0 \%$ of fibre content. Within this interval the residual velocity dropped from $32 \%$ of its impact value to $9 \%$ of its impact value. Further increase of fibre content brought still some improvement, but the biggest one lies around $2 \%$ of fibre content by volume (Figure 3).

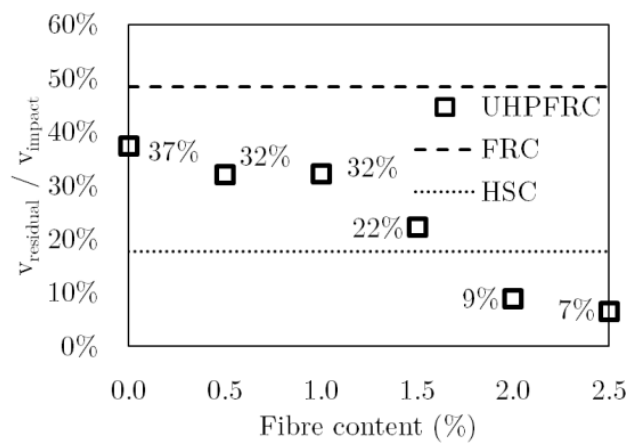

Figure 3: Residual to impact velocity ratio of the non-deformable projectile.

Influence of the fibre content on the residual velocity of the projectile was sufficiently confirmed by the number of the perforated steel plates. Steel plates were perforated only by the steel core of the projectile. Perforation of 1.5 plates could by a life threatening event for a human body. Less than 1.5 perforated steel plates in average were gained only within UHPFRC mixtures with $2.0 \%$ and $2.5 \%$ of fibre content (Figure 4 ).

Implementation of relatively small fibre content enhanced the behaviour in terms of debris fragment mass significantly. Secondary fragments, i.e. fragments generated by the scabbing of the slab, could be as dangerous as primary fragments attacking the slab. Significant reduction of the debris fragment mass is evident within the interval between plain mixture and mixture containing $1.0 \%$ 


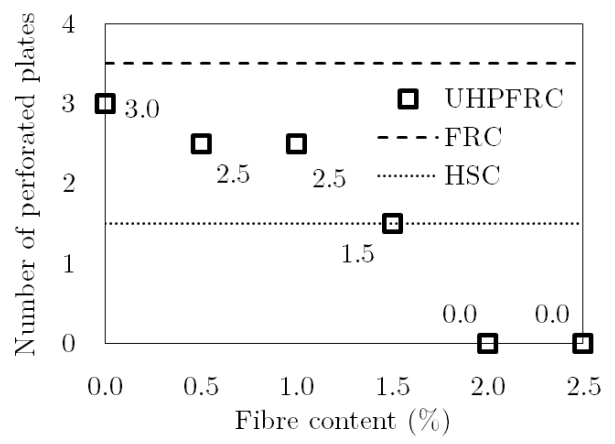

Figure 4: Number of perforated steel plates.

of fibres. The debris fragment mass was reduced from 560 grams (plain UHPC mixture) to 99 grams (UHPFRC mixture with $1.0 \%$ of fibre content). Further increase of fibre content above $1.0 \%$ did not bring any significant improvement to the debris fragment mass (Figure 5).

Taking into account both residual velocity and debris fragment mass, it can be stated that optimal fibre content in UHPFRC with respect to non-deformable projectile impact is $2.0 \%$ by volume.

Conventional materials such as HSC or FRC did not show sufficient resistance to projectile impact compared to UHPFRC. Either HSC showed sufficient behaviour in terms of residual velocity but did not show sufficient capacity to retain secondary fragments or FRC showed good resistance in terms of debris fragment mass but failed in terms of residual velocity of the projectile. This was further confirmed by the number of perforated steel plates.

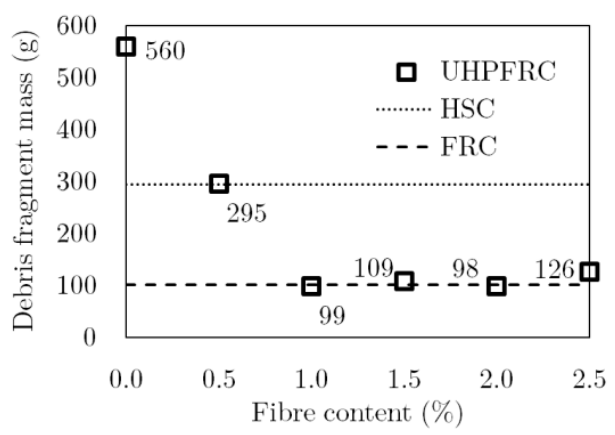

Figure 5: Debris fragment mass after the non-deformable projectile impact.

HSC presented good resistance in terms of the residual velocity of the projectile due to the presence of coarse aggregate. Coarse aggregate is believed to improve the impact resistance of the concrete targets significantly [7, 20]. Thus, residual velocity of the projectile after perforating HSC fell below the UHPFRC with $1.5 \%$ of fibre content. Nevertheless, debris fragment mass of 
the HSC under the projectile impact was at the level of UHPFRC with $0.5 \%$ of fibre content.

On the other hand, conventional FRC had reasonably good response in terms of debris fragment mass, where the debris fragment mass reached the level of UHPRC with $2.0 \%$ of fibre content. However, response to projectile impact in terms of the residual velocity was very poor (Figure 3 ).

Values shown in the graphs are arithmetic means of four values.

\section{Conclusions}

This study was focused on the residual velocity of the non-deformable in-service projectile after perforating UHPFRC slabs where the fibre content was selected as the main test variable. Together 24 UHPFRC slabs with different fibre content ranging from $0 \%$ to $2.5 \%$ were tested. In addition, convention materials such as HSC and FRC were tested for comparison. It was concluded that UHPFRC is a material with high potential for protective structures, because its response was much better that in case of HSC or FRC. Furthermore it was stated that the optimal fibre content of UHPFRC with respect to the non-deformable projectile impact is $2 \%$ by volume.

\section{Acknowledgements}

The authors gratefully acknowledge the support provided by the Ministry of Education, Youth and Sports under the bilateral project number LH12168 Behaviour of High-Performance Fibre-Reinforced Cementitious Composites Subjected to Extreme Loading. The authors would also like to acknowledge the assistance given by the technical staff of the Experimental Centre, CTU in Prague and by students who participated in the project.

\section{References}

[1] Ohno, T., Uchida, N., Ishikawa, Y., Kasai, H., Tsubota, M., Ueda, A., et al., Improvement on impact resistance of reinforced concrete panels against projectile impact. Structures Under Shock and Impact III. Proceedings of the 3rd International Conference. Madrid, Spain, WIT Press (UK), pp. 254-260, 1994.

[2] Wang, N., Mindess, S., Ko, K., Fibre reinforced concrete beams under impact loading. Cem. Concr. Res., 26, pp. 363-376, 1996.

[3] Habel, K., Gauvreau, P., Response of ultra-high performance fiber reinforced concrete (UHPFRC) to impact and static loading. Cement and Concrete Composites, 30, pp. 938-946, 2008.

[4] Maalej, M., Quek, S. T., Zhang, J., Behavior of hybrid-fiber engineered cementitious composites subjected to dynamic tensile loading and projectile impact. J. Mater. Civ. Eng., 17, pp. 143-152, 2005.

[5] Arias, A., Forquin, P., Zaera, R., Impact damage in concrete targets subjected to perforation of high velocity metallic fragment. DYMAT- 
International Conference on the Mechanical and Physical Behaviour of Materials under Dynamic Loading, EDP Sciences, pp. 1215-1221, 2009.

[6] Dancygier, A. N., Yankelevsky, D. Z., Jaegermann, C., Response of high performance concrete plates to impact of non-deforming projectiles. Int. J. Impact Eng., 34, pp. 1768-1779, 2007.

[7] Zhang, M., Shim, V., Lu, G., Chew, C., Resistance of high-strength concrete to projectile impact. Int. J. Impact Eng., 31, pp. 825-841, 2005.

[8] Vossoughi, F., Ostertag, C. P., Monteiro, P. J., Johnson, G. C., Resistance of concrete protected by fabric to projectile impact. Cem. Concr. Res., 37, pp. 96-106, 2007.

[9] Soe, K. T., Zhang, Y. X., Zhang, L. C., Impact resistance of hybrid-fiber engineered cementitious composite panels. Composite Structures, 104, pp. 320-330, 2013.

[10] Tai, Y. S., Flat ended projectile penetrating ultra-high strength concrete plate target. Theor. Appl. Fract. Mech., 51, pp. 117-128, 2009.

[11] Máca, P., Sovják, R., Resistance of ultra high performance fibre reinforced concrete to projectile impact. Structures Under Shock and Impact, 126, pp. 261, 2012.

[12] Sovják, R., Vavřiník, T., Máca, P., Zatloukal, J., Konvalinka, P., Song, Y., Experimental Investigation of Ultra-high Performance Fiber Reinforced Concrete Slabs Subjected to Deformable Projectile Impact. Procedia Engineering, 65, pp. 120-125, 2013.

[13] Maca, P., Zatloukal, J., Konvalinka, P., Development of Ultra High Performance Fiber Reinforced Concrete mixture. IEEE Symposium on Business, Engineering and Industrial Applications (ISBEIA), IEEE, pp. 861-866, 2012.

[14] Máca, P., Sovják, R., Konvalinka, P., Mixture Design and Testing of Ultra High Performance Fiber Reinforced Concrete. Malaysian Journal of Civil Engineering, 25 Special Issue (1), pp. 74-87, 2013.

[15] Máca, P., Sovják, R., Vavřiník, T., Experimental Investigation of Mechanical Properties of UHPFRC. Procedia Engineering, 65, pp. 14-19, 2013.

[16] Máca, P., Sovják, R., Konvalinka, P., Mix Design of UHPFRC and its Response to Projectile Impact. Int. J. Impact Eng., 2013.

[17] BP Kneubuehl, Ballistics (in Czech), Naše vojsko, Prague, 2004.

[18] Bludau, C., Keuser, M., Kustermann, A., Perforation resistance of highstrength concrete panels. ACI Struct. J., 103, 2006.

[19] Børvik, T., Langseth, M., Hopperstad, O., Polanco-Loria, M., Ballistic perforation resistance of high performance concrete slabs with different unconfined compressive strengths. Proceedings of first international conference on high performance structures and composites. Sevilla, Spain: WIT press (ISBN 1-85312-904-6), pp. 273-282, 2002.

[20] Werner, S., Thienel, K., Kustermann, A., Study of fractured surfaces of concrete caused by projectile impact. Int. J. Impact Eng., 52, pp. 23-27, 2013. 